\title{
Medicina Interna
}

Internal Medicine

\section{$\mathrm{Ml}-1$}

\section{MIOPATÍA NECROTIZANTE INFLAMATORIA AUTOINMUNE ASOCIADA A ESTATINAS}

\author{
ARAGÓN DIANA, DUARTE JUAN, MAYORGA CAROL, SUÁREZ LILIA, \\ ZAMBRANO MARÍA.
}

Departamento de Medicina Interna, Hospital Universitario de la Samaritana, Bogotá, D.C., Colombia.

Introducción. Las estatinas no solo han revolucionado el tratamiento de la hipercolesterolemia en pacientes con alto riesgo cardiovascular, también han proporcionado múltiples beneficios adicionales conocidos como efectos pleiotrópicos. No obstante, la miopatía secundaria a este tratamiento representa un 7 a $29 \%$, restringiendo su uso en algunos pacientes. La severidad de la sintomatología depende de la elevación en los niveles de creatin kinasa (CK), presentándose desde debilidad y mialgias hasta falla renal, hepática e incluso la muerte. Pocos casos de miopatía necrotizante fulminante secundario al uso de estatinas han sido descritos.

Diseño. Estudio descriptivo de tipo reporte de caso.

Métodos. Informe de caso.

Resultados. Paciente femenina de 34 años con antecedente de dislipidemia, hipertensión arterial, obesidad, síndrome de apnea del sueño y trastorno cognitivo, quien tras un periodo corto de consumo de atorvastatina a alta dosis presentó cuadro de debilidad muscular progresiva, con dolor y dificultad para la marcha. Durante las primeras 48 horas del ingreso al hospital presentó rápida progresión de debilidad muscular requiriendo ventilación mecánica invasiva, manejo en cuidado intensivo con desenlace fatal.

Al ingreso se evidenció valores de CK muy elevados (7727 UI/L), con aumento progresivo y sin mejoría tras la suspensión de estatina. Cursó con rabdomiolisis severa, falla renal y fenómeno de inmunosupresión severa. La biopsia muscular reportó múltiples fibras degeneradas de aspecto ondulante rodeadas por infiltrado mixto, predominantemente mononuclear linfocitario en parches. Se consideró miopatía necrotizante inflamatoria inmune secundario a uso de estatinas.

Conclusiones. La miopatía necrotizante inmune asociada a estatinas es una complicación infrecuente pero severa, debe sospecharse ante síntomas musculares severos que persisten pese al retiro del fármaco, elevación marcada de CK, lesión renal e inmunosupresión. 


\title{
MI-2
}

\section{RESPUESTA AL MANEJO MULTIDISCIPLINARIO DEL PIE DIABÉTICO: A PROPÓSITO DE 3 CASOS CLÍNICOS}

\author{
DOMÍNGUEZ RUIZ JUAN DIEGO, DÍAZ ROSALES YURANY ANDREA, \\ CERÓN MORA NATHALY YISET, HERMIDA ORTIZ CINDY ALEJADRA, \\ RODRÍGUEZ FLÓREZ ROBERTO JOSE, PINZÓN TOVAR ALEJANDRO.
}

\author{
Hospital Universitario Hernando Moncaleano Perdomo, Neiva, Colombia.
}

Introducción. El pie diabético es la principal causa de amputación no traumática en el mundo. El conjunto de factores como neuropatía periférica, enfermedad vascular, pobre control glicémico y deformidades ortopédicas, solos o en combinación, pueden causar ulceras e infecciones y finalmente la perdida de la extremidad. En Colombia, en Medellín y Cartagena, la prevalencia fue de 5.8 y $19 \%$ respectivamente. La amputación en personas con diabetes es 10 a 20 veces más frecuente al compararlos con no diabéticos y $1 / 3$ de los costos de la diabetes están relacionados con ulceras en el pie.

\section{Presentación de casos.}

Caso 1: Paciente femenina de 68 años, diabética e hipertensa sin tratamiento, consulta por ulcera en primer artejo izquierdo asociado a secreción purulenta y fiebre. Glicemia de ingreso $400 \mathrm{mg} / \mathrm{dl}$. Se realiza amputación del primer dedo y desbridamiento de tejido necrótico en región plantar.

Caso 2. Paciente masculino de 48 años, diabético, ingresa por lesión abscedada en región plantar izquierda asociado a fiebre. Glicemia de ingreso $504 \mathrm{mg} / \mathrm{dl}$. Se lleva a lavado quirúrgico encontrando necrosis del tercio medio plantar del pie y antepie que se extiende hasta la cara medial del tobillo.

Caso 3. Paciente masculino de 62 años, diabético, ingresa por ulcera a nivel del talón izquierdo asociado a secreción purulenta. Glicemia de ingreso $421 \mathrm{mg} / \mathrm{dl}$. En lavado quirúrgico se encuentra ulcera de $3 \times 3 \mathrm{~cm}$ con exposición del tendón de aquiles y secreción fibrinopurulenta.

A los pacientes se les inicio control metabólico estricto y terapia de presión negativa, presentando adecuada granulación del tejido y posterior realización de injerto de piel, como se tiene documentado en el registro fotográfico.

Discusión. El manejo integral del pie diabético por endocrinología, clínica de heridas, ortopedia, cirugía plástica, psicología y nutrición, disminuye el riesgo de amputación de la extremidad y mejora la calidad de vida de los pacientes. 


\section{MI-3}

\section{NEUROPATÍA VASCULITICA MEDIADA POR ANCA}

\section{MILLÁN HENRY AUGUSTO, LUNA FREDYANDRÉS, PÉREZ MARÍA ALEJANDRA, RAMOS MARÍA ELENA.}

Universidad nuestra señora del Rosario, Hospital mayor de Méderi, Bogotá, D.C.,Colombia.

Introducción. La neuropatía vasculíticaes una condición asociada a vasculitis sistémicasprincipalmente ANCA (anticuerpos anti citoplasma de neutrófilo) positivas. Usualmente tiene un inicio abrupto y rápida progresión; además de su baja incidencia y pronostico ominoso, implica un diagnóstico tardío en la mayoría de los casos.

Reporte de caso. Paciente de sexo masculino de 58 años.Consulta por 2 meses de evolución con perdida de $12 \mathrm{~kg}$ de peso, episodios febriles, fatiga, hipostesia y disestesias en miembros inferiores de predominio distal que progresa a miembros superiores. Al ingreso se evidencióparálisis facial periférica izquierda, disminución de la fuerza en grupos musculares distales de extremidades, reflejos disminuidos, pie caído izquierdo, respuesta plantar indiferente bilateral, hipoestesia en guante y bota larga bilateral con alodinia. Durante estancia hospitalaria presenta disfagia y empeoramiento de la paraparesiacon arreflexia.Los anticuerpos anti mieloperoxidasa fueron positivos, con antiproteinasa 3negativos.La electromiografía fue compatible con polineuropatía crónica motora y sensitiva axonalsevera; la biopsia de nervio suralconfirmó vasculitis en fase evolutiva. No presentaba compromiso en otro sistema. Se concluyó que cursaba con poli angeítis microscópica (PAM) y recibiócorticoide sistémico, ciclofosfamida y azatioprina con evidencia de mejoría en función motora, resolución de disestesias y fiebre.

Discusión. La PAM presenta compromiso en sistema nervioso central en el 15\% de los casos y periférico en el 50\%. Los síntomas constitucionales se presentan en el 70\% de los pacientes y pueden estar presentes meses previos a la afectación nerviosa. El nervio peroné es el más afectado, sin embargo la progresión puede ser rápida llevando a neuropatía multifocal generalizada como en el caso presentado.

Conclusión. La respuesta al tratamiento es variable con secuelas que incluyen dolor o paresia. El principal factor pronóstico asociado es el inicio rápido del tratamiento por lo que esta patología requiere un rápido reconocimiento. 


\title{
$\mathrm{Ml}-4$
}

\section{RABDOMIOLISIS SECUNDARIA A EJERCICIO Y CONSUMO DE ALCOHOL}

\author{
FIGUEREDO-PEÑA MARÍA DEL CARMEN, MOLINA-PIMIENTA \\ LUISANA, RUIZ-TALERO PAULA.
}

Departamento de Medicina Interna, Pontificia Universidad Javeriana, Hospital Universitario San Ignacio, Bogotá, D.C., Colombia.

Introducción. La rabdomiolisis es un síndrome clínico caracterizado por dolor muscular, parestesias y mioglobinuria. Su etiología es variada y puede asociarse con ejercicio, trauma y consumo de alcohol. El espectro de severidad puede ir desde la ausencia de síntomas hasta la lesión renal aguda. Se presenta el caso de un paciente con rabdomiolisis secundaria a consumo de alcohol y ejercicio extenuante.

Material y Métodos. Estudio descriptivo, reporte de caso.

Resultados. Paciente masculino de 19 años previamente sano con cuadro clínico de 3 días caracterizado por dolor en miembros inferiores durante el reposo y la flexión asociado a edema, limitación de la marcha y coluria llevándolo hasta la postración en cama. Al interrogatorio dirigido refiere que suspendió actividad física hace 6 meses con reinicio de la misma en los últimos 4 días con una intensidad de 2 horas al día e ingesta de 15 cervezas en mismo periodo de tiempo. Al examen físico de ingreso con signos de deshidratación. Paraclínicos con creatinina normal, uroanálisis que muestra hematuria y piuria, elevación de las transaminasas y CPK (creatina-fosfocinasa) total de $142.315 \mathrm{U} / \mathrm{L}$. Se diagnostica rabdomiolisis probablemente secundaria al consumo de alcohol y ejercicio intenso. Se indicó reanimación hídrica exhaustiva con evolución clínica favorable, descenso de CPK y transaminasas, recuperación de fuerza y ausencia de dolor.

Conclusión. La rabdomiolisis es una entidad que requiere diagnóstico temprano para evitar complicaciones. La sospecha clínica y el diagnóstico precoz en este caso evitó complicaciones mayores como lesión renal aguda y su evolución clínica fue satisfactoria. Se requiere educación a los pacientes para evitar el consumo de alcohol en conjunto con el ejercicio como prevención. 


\title{
MI-5
}

\section{DELIRIUM: IDENTIFICACIÓN OPORTUNA Y MANEJO TRANSVERSAL DE LAS INTERACCIONES FARMACOLÓGICAS}

\author{
ZAPATA-CRISTANCHO D.C., VALENCIA-MONSALVE A.M., MUÑOZ- \\ TORRES C.E., CASTAÑEDA $X$.
}

Fundación Cardioinfantil - Instituto De Cardiología, Bogotá, D.C., Colombia.

Introducción. El delirium es una condición clínica que afecta a un tercio de los adultos mayores al momento de la hospitalización o durante su estancia. (1) Los factores de riesgo asociados se han clasificado como predisponentes y precipitantes. (2) Identificar tempranamente las interacciones farmacológicas que precipitan el delirium hace parte del manejo integral enfocado en la seguridad del paciente.

Métodos. Descripción narrativa de la atención transversal prestada a un paciente que presentó delirium como consecuencia de múltiples factores, identificándose problemas, causas y posibles intervenciones.

Resultados. Paciente masculino de 71 años con antecedentes de miopatía inflamatoria autoinmune en manejo con deflazacort y osteomielitis (OM) por Candida albicans. Al sexto día de tratamiento con fluconazol, el paciente presentó delirium mixto: alucinaciones visuales y auditivas, confusión y alteración del juicio y raciocinio.

Sin mejoría con antipsicótico y descartando infecciones sistémicas, causas metabólicas, hidroelectrolíticas, neurológicas y psiquiátricas, se consultó al servicio farmacéutico para evaluación de la farmacoterapia encontrando múltiples interacciones farmacológicas. Se recomendó suspender el deflazacort observando resolución del cuadro durante las 72 horas siguientes.

El análisis del programa de Farmacovigilancia concluyó que el delirium fue una reacción adversa a medicamentos (RAM) probable por interacción entre deflazacort y fluconazol según el algoritmo de Naranjo y lo descrito en la literatura.

Conclusiones. La farmacoterapia constituye un aspecto crítico que debe monitorizarse y evaluarse de manera concurrente entre el farmacéutico y el clínico a fin de evitar complicaciones por interacciones farmacológicas.

Desde la perspectiva farmacéutica, este caso acentúa la importancia de participar activamente en el manejo transversal y toma de decisiones para beneficio y seguridad del paciente.

La manifestación de efectos adversos relacionados con el medicamento puede coincidir con signos y síntomas que clínicamente orientan a otros diagnósticos. Es necesario intuir, buscar y conocer las diferentes interacciones farmacológicas del paciente poli medicado como parte del diagnóstico. 


\title{
MI-6
}

\section{SÍNDROME HEMOLÍTICO URÉMICO ATÍPICO: DESCRIPCIÓN DE 20 CASOS DE LA REGIÓN CARIBE COLOMBIANA}

\author{
AROCA MARTÍNEZ GUSTAVO, CABARCAS OMAR, GONZÁLEZ- \\ TÓRRES HENRY, DOMÍNGUEZ-VARGAS ALEX, CONDE JUAN, \\ OROZCO JOSÉ, ARARAT EDUFAMIR ${ }^{A}$, MUSSO CARLOS, CONDE JUAN, \\ CADENA ANDRÉS.
}

Facultad de Ciencias de la Salud, Universidad Simón Bolívar. Departamento de Nefrología, Clínica de la Costa, Barranquilla, Colombia.

Instituto Universitario del Hospital Italiano, Buenos Aires, Argentina.

Introducción. El Síndrome Hemolítico Urémico Atípico (SHUa) es una patología rara, inflamatoria y genética asociada a una alta morbimortalidad. Se caracteriza por la triada de: anemia hemolítica microangiopática, trombocitopenia y lesión en órgano blanco. Los registros de pacientes son importantes herramientas que permiten caracterizar la historia natural de las enfermedades, evaluar terapias clínicas, monitorizar la seguridad de los medicamentos y medir la sobrevida de los pacientes. En Colombia, existe escasez de estudios que permitan describir las características clínico-epidemiológicas del SHUa. El objetivo del presente estudio es describir el primer registro del SHUa en el caribe colombiano.

Diseño. Estudio multicéntrico, descriptivo y retrospectivo

Métodos. Se incluyeron 20 pacientes durante el periodo del 2014 al 2017 en el que participaron 5 centros médicos de la Región Caribe colombiana. Fueron excluidos pacientes con niveles de ADAMST-13 $(<10 \%)$ y con presencia de toxina shiga positiva en heces. Se registraron parámetros clínicos, inmunológicos y genéticos: mutaciones en los seis factores de susceptibilidad para SHUa y para anticuerpos anti-factor $\mathrm{H}$.

Resultados. Del total de pacientes, $79 \%$ fueron femeninas, la edad promedio fue de $41 \pm 17.2$ años. La manifestaciones hematológicas $(100 \%)$, renales $(90 \%)$ y gastrointestinales $(65 \%)$ fueron las más frecuentes. En 4/15 femeninas el SHUa estuvo asociado al embarazo, de las cuales $2 / 4$ evidenciaron preeclampsia. El lupus $(2 / 20)$ y la esclerodermia (1/20) se manifestaron concomitantemente. $14 / 20$ pacientes presentaron esquistocitos en frotis de sangre periférica. El valor promedio de ADAMST-13 fue de $66 \%$. El 93\% de los pacientes recibieron plasmaféresis. 11/20 (57\%) pacientes requirieron de terapia de reemplazo renal. La mutación genética más frecuente fue sobre el factor $\mathrm{H}(\mathrm{CFH})(15 \%)$.

Conclusiones. Este reporte se constituye en el primer registro colombiano de SHUa. Es necesario realizar estudios de seguimiento para evaluar la sobrevida y el impacto de tratamientos específicos. 


\title{
MI-7
}

\section{ENFERMEDAD DEL SUERO POSTERIOR A COLOCACIÓN DE SUERO ANTIOFIDICO: UNA COMPLICACIÓN INFRECUENTE A TENER EN CUENTA}

\author{
ALVAREZ PERDOMO LUIS CARLOS, MOTTA QUIMBAYA ORFA, \\ GIRALDO BAHAMON GERMAN, ZAMORA JARAMILLO ADRIANA, \\ PUENTES CASTRILLON MARIA ELCY, VILLALBA CERQUERA \\ YESICA.
}

\author{
Hospital Universitario Hernando Moncaleano Perdomo, Universidad \\ Surcolombiana, Neiva, Colombia.
}

Introducción. El accidente ofídico es un problema de salud pública debido a la importante morbilidad y mortalidad que genera especialmente en zonas tropicales, con estimación mundial de 1,2 a 5,5 millones de mordeduras de serpiente anual y nacional de 9,7 casos por 100.000 habitantes, con mortalidad de 0.3 casos por millón habitantes. El accidente bothrópico representa el 80-90\% de los accidentes ofídicos con guía de manejo en caso probable y confirmado de suero antiofídico polivalente con el cual se han documentado reacciones adversas asociadas dentro de estas como manifestación adversa tardía la enfermedad del suero.

Presentación del caso. Hombre de 18 años, soldado profesional quien sufre mordedura por serpiente de especie no conocida en antebrazo izquierdo con manifestación de edema, dolor moderado y parestesias locales. Se considero accidente ofídico posible bothrópico leve con indicación de 8 ampollas se suero polivalente. Ocho días después presenta lesiones tipo habones pruriginosos generalizados que evolucionan a lesiones morbiliformes maculares y placas eritematosas purpuricas de predominio en extremidades inferiores, asociado a mialgias, artralgias y fiebre. Estudios documentan consumo del complemento, con biopsia compatible con vasculitis leucocitoclástica con depósito de inmunoglobulinas M, A y $\mathrm{C} 3$ en la pared de vasos dérmicos que este contexto clínico es compatible con enfermedad del suero. Recibió manejo con esteroides con resolución completa del cuadro clínico.

Discusión. La enfermedad del suero es una reacción tardía de hipersensibilidad tipo III mediada por inmunocomplejos que ocurre entre el día 5 a 14 posterior a exposición de suero antiofídico. Presentamos un caso con documentación clínica y confirmación histopatológica con inmunofluorescencia directa de esta rara presentación descrita en el 5\% dentro de las manifestaciones totales de reacciones adversas por suero polivalente, así como los factores de riesgo asociados a la dosis que en nuestro caso no fue correcta según directrices del instituto nacional de salud. 


\section{MI-8}

\section{ERGOTISMO: UN RETO TERAPÉUTICO}

\section{RUEDA DIANA, RUIZ CAMILO, NAVARRO KAREN, ALARCÓN PILAR.}

Hospital Universitario San Ignacio, Pontificia Universidad Javeriana, Bogotá, D.C., Colombia

Introducción. El $0.001 \%$ de los pacientes consumidores de ergotamina desarrollan isquemia vascular periférica por estimulación de los receptores alfa adrenérgicos y 5-HT2A. Los inhibidores de proteasa aumentan los niveles séricos de medicamentos derivados del ergot a través de la inhibición del citocromo P450- isoenzima CYP34a, lo que predispone al desarrollo de ergotismo existiendo dos tipos: convulsivo y gangrenoso, el primero con mayor compromiso sistémico y el segundo con predominio vascular que en ocasiones conlleva a amputaciones.

Objetivo. Describir caso clínico de ergotismo con énfasis en el tratamiento y su desenlace

Método. Estudio descriptivo, reporte de caso

Resultados. Hombre de 34 años con infección por VIH en tratamiento con lamivudina/ zidovudina y atazanavir/ ritonavir; recibió adicionalmente ergotamina durante 2 semanas previas al ingreso por cefalea. Consultó por cinco días de acrocianosis simétrica, dolorosa, con limitación funcional. Al examen físico con cianosis de manos y pies, disminución de pulsos y frialdad distal, doppler arterial confirmó vasoespasmo y descartó trombosis, se inició calcioantagonista y anticoagulación, ante ausencia de mejoría, se decidió inicio de nitroglicerina y vigilancia en cuidados intermedios, respuesta favorable por mejoría de la perfusión, adecuado control del dolor, se descartó neuroinfección. Se dió egreso con reinicio de terapia antirretroviral.

Conclusiones. El ergotismo constituye un reto diagnóstico y terapéutico cuya evidencia científica disponible está basada en reportes de casos dado la baja incidencia de la enfermedad. Desde 1975 se han descrito múltiples manejos que comprenden venodilatadores y dilatación arterial endovascular", pero ninguno se constituye como la piedra angular frente al manejo.

El reconocimiento oportuno de esta entidad, asociado a la suspensión de la ergotamina y el manejo vasodilatador temprano son factores influyentes sobre el curso incierto de esta enfermedad en pro de evitar pérdida de extremidades. 


\section{MI-9}

\section{SÍNDROME DE LÖFGREN EN NEIVA-COLOMBIA: REPORTE DE UN CASO}

\section{POVEDA-CONDE LITHEY CRISTINA, RODRÍGUEZ-PARRA MARÍA ALEJANDRA, CORTÉS-GUZMÁN JOSÉ SANTIAGO, DURÁN- GUTIÉRREZ LUIS FERNANDO.}

Hospital Universitario Hernando Moncaleano Perdomo, Neiva-Huila, Colombia.

Introducción. La sarcoidosis es una enfermedad inflamatoria crónica granulomatosa de etiología desconocida. Tiene una forma de presentación aguda conocida como Síndrome de Löfgren, caracterizado por la triada: linfadenopatía hiliar bilateral, eritema nodoso e inflamación periarticular de los tobillos.

Presentación del caso. Paciente masculino de 37 años con antecedente de hipertensión arterial y diabetes mellitus tipo 2 , que ingresó por cuadro clínico de un mes de artralgias, inicialmente en rodillas y tobillos, luego en hombros y carpos, además, picos febriles intermitentes y aparición de rash en las 4 extremidades. Al examen físico se encontró poliartritis y eritema nodoso. En los paraclínicos se evidenció hipotiroidismo subclínico. Se tomó una radiografía de tórax que mostraba imágenes sugestivas de adenopatías hiliares y signos de hipertensión pulmonar precapilar. Posteriormente, se solicitó una tomografía de tórax que mostró múltiples adenopatías subcarinales, paratraqueales, parahiliares, mediastinales mayores a $1 \mathrm{~cm}$ de diámetro, aumento de tamaño de estructuras vasculares pulmonares y opacidades pulmonares en vidrio esmerilado.

Adicionalmente, se realizó biopsia de lesiones en piel del miembro superior izquierdo, cuyo estudio histopatológico reportó paniculitis lobular granulomatosa sugestiva de sarcoidosis; se realizaron coloraciones especiales (PAS,Ziehl-Neelsen, plata metamina de Grocott) y se confirmó diagnóstico de Síndrome de Löfgren. Se inició manejo con corticoides orales y se dió egreso al paciente con prednisolona oral $50 \mathrm{mg}$ al día, con resolución de sintomatología.

Discusión. El síndrome de Löfgren es una forma de sarcoidosis de presentación aguda, ocurre en menos del 5 al 10\% de sarcoidosis, es más frecuente en mujeres y suele ser autolimitada. En Colombia, la sarcoidosis y su variante síndrome de Löfgren se deben tener siempre en cuenta como diagnóstico diferencial en pacientes con eritema nodoso y/o adenopatías hiliares, a pesar de su baja prevalencia.

Palabras clave (DeCs): Sarcoidosis, Síndrome de Löfgren, Eritema nodoso. 
MI-10

\title{
MIASIS, UN PROBLEMA OLVIDADO DE SALUD PÚBLICA HUMANA: SERIE DE CASOS
}

\author{
SIERRA-MERLANO RITA-M, BALAGUERA CESAR, VILLADIEGO- \\ BARRIOS JEAN.
}

Universidad de Cartagena, Cartagena, Colombia.

Resumen.La miasis es una enfermedad infecciosa prevenible descrita como un problema de Salud Pública humana en Colombia desde el siglo pasado y aun representa una causa frecuente de hospitalización, morbilidad y mortalidad sin nuevas investigaciones que llamen la atención sobre esta entidad.

Objetivos. Describir las características sociodemográficas de la miasis en una serie de casos hospitalaria en Cartagena.

Metodología. Observacional. Descriptivo. Serie de casos hospitalaria.

Resultados. Entre octubre de 2016 hasta marzo de 2018 encontramos 138 casos-egresos de miasis en el hospital objeto de estudio. La edad de presentación fue de 18 a 97 años, sexo masculino $61 \%$, el $98.5 \%$ de los casos fue no-nosocomial y el 1,5\% nosocomiales, no hubo casos foráneos. El 52,2\% fue urbano, siendo el $18 \%$ a habitantes de la calle. El factor de riesgo más frecuente fue: trauma sin atención oportuna ( $42 \%)$. La localización anatómica fue cutánea: miembro inferior $(62,3 \%)$, cara $(11,6 \%)$ y cuero cabelludo $(9,5 \%)$. La mediana de permanencia hospitalaria fue nueve días-camas (RIC de 7-16), con estancias mayores para los casos masculinos y los adultos-mayores de 65 años. Las larvas, ni las moscas no fueron aisladas ni identificadas.

Conclusión. En Colombia la investigación científica de miasis es en Salud Pública veterinaria. No hay investigación relevante de miasis humana. Diferente a lo publicado en Latinoamérica y Colombia, en esta serie la miasis-nosocomial fue el 1,5\% y no hubo foráneos. La miasis humana sigue siendo causa frecuente de hospitalización, siendo una enfermedad: prevenible, ligada a la pobreza que afecta las poblaciones más vulnerables. La investigación entomológica y de Salud Pública de la enfermedad en humanos es deficiente. 
MI-11

\section{DIABETES INSÍPIDA CENTRAL SECUNDARIAA MENINGOENCEFALITIS VIRAL}

\section{MORENO PALLARES E., BORNACELLY MENDOZA A.}

Universidad de Cartagena, Fundación Universitaria Navarra. Cartagena, Colombia.

Objetivo. Presentar caso de diabetes insípida central secundaria a meningoencefalitis viral

Diseño del estudio. Presentación de caso clínico

Lugar del estudio. Hospital Universitario del Caribe, Cartagena, Colombia

Metodología. Caso de diabetes insípida central secundaria a meningoencefalitis viral

Caso Clínico. Masculino de 61 años, raza mestiza, antecedentes patológicos de hipertensión arterial crónica primaria, ingresa a urgencias por cuadro clínico 24 horas evolución de picos febriles subjetivos asociado a cefalea con signos de banderas rojas, alteración del estado de conciencia con posterior convulsión tónico-clónica generalizada, un episodio con duración de 5 minutos que cesó de forma autolimitada con recuperación progresiva de su conciencia. Signos vitales: FC: 83 lpm, FR:14 rpm, TA: $123 / 70 \mathrm{mmHg}, \mathrm{T}: 39.5^{\circ} \mathrm{c}$, Peso $80 \mathrm{~kg}$, Talla $1.75 \mathrm{mts}$, Glasgow 12 (apertura ocular a la voz, respuesta verbal: confuso, respuesta motora: localiza el dolor), mucosa oral sin lesiones, isocorias reactivas a la luz como reflejo fotomotor y consensual preservado, fondo de ojo sin evidencia de papiledema, sin compromiso de pares craneales, cuello con signos meníngeos claros: Brudzinsky, Kernig y signo de la sacudida positivo, sin evidencia de adenopatías cervicales. Neurológico: somnoliento, fuerza y sensibilidad conservada, rot ++ , rigidez en extremidades, romberg negativo, marcha con aumento del polígono de sustentación, babinski negativo. Tac cráneo simple sin evidencia de lesiones solidas ni signos tempranos de isquemia ni sangrado, se inició manejo con corticoides más antibioticoterapia para meningitis de forma empírica: ceftriaxona + vancomicina + ampicilina IV; además agregando Aciclovir $800 \mathrm{mg}$ cada 8 horas IV pensando en meningoencefalitis viral, punción lumbar con proteinorragia, gram y cultivo negativo, por lo cual se suspendieron antibióticos y se continuó antivirales con adecuada respuesta clínica y paraclínica, en el día quinto de hospitalización presenta diuresis de 18 litros asociado a polidipsia, osmolaridad urinaria disminuida y plasmática aumentada, test de osmolaridad urinaria tras vasopresina 980, RMN cerebral que descarta isquemia o tumores hipofisiarios (imagen), se diagnostica diabetes insípida central secundaria a meningoencefalitis viral, se inició manejo con desmopresina con adecuada respuesta por lo cual se dio egreso y cita por consulta externa.

Conclusión. La diabetes insípida (DI) central generalmente es causada por la producción y/o secreción inadecuada de vasopresina de la glándula pituitaria en respuesta a la estimulación osmótico. La DI central con mayor frecuencia es causada por la destrucción traumática o tumores de la neurohipófisis, las infecciosas constituyen el 9\% de las causas de DI central. En este paciente se diagnostica DI central secundaria a meningoencefalitis viral por clínica y paraclínicos como osmolaridad sérica aumentada y urinaria baja, osmolaridad urinaria tras vasopresina $>750 \mathrm{mOsmmol} /$ $\mathrm{Kg}$, osmolaridad urinaria tras restricción hídrica $<300 \mathrm{mOsmmol} / \mathrm{Kg}$. El tratamiento se basa en sustitución con desmopresina. 